\title{
SIMULASI PENDETEKSI KELEMBABAN PADA TANAH MENGGUNAKAN SENSOR DHT22 DENGAN PROTEUS
}

\author{
Ahmad Roihan', Aditya Mardiansyah², Adlan Pratama ${ }^{3}$, Akmal Ardhi Pangestu ${ }^{4}$ \\ 1,2,3,4 Prodi Sistem Komputer Universitas Raharja \\ ahmadroihan@gmail.com
}

\begin{abstract}
This study aims to provide convenience for farmers and orchid lovers. Because giving water to orchid plants requires special attention, if the orchid plant has too much water at the time of watering, the orchid plant cannot grow optimally and vice versa, if the orchid plant at the time of watering, the orchid plant lacks water then the orchid plant does not grow optimally, This tool uses a DHT22 sensor. Answering this problem, the researchers created an automatic orchid sprinkler with a DHT 22 sensor. The DHT22 sensor was chosen over the DHT11 sensor because it has a wide measurement range, namely 0 to $\mathbf{1 0 0 \%}$ for humidity and $\mathbf{- 4 0}$ degrees Celsius to 125 degrees Celsius for temperature. This sensor also has a high-accuracy digital output. DHT 22 requires a supply voltage of 2.4 and $5.5 \mathrm{~V}$. Serial clock input is used to synchronize communication between the microcontroller and DHT22, then it is used to transfer data from and to DHT22. Product trials are carried out to determine the performance of products that have been made and product revisions are made if there are errors, then trial use on orchid plants.
\end{abstract}

Keywords: humidity sensor, 22 . DHT sensor

\section{PENDAHULAN}

Teknologi semakin pesat, sehingga kebutuhan manusia semakin banyak yang bergantung pada teknologi baik dalam bidang komunikasi, pendidikan maupun pertanian. Sampai saat ini, teknologi yang membantu manusia di bidang pertanian masih dianggap kurang berkembang[1]. Karena sebagian petani besar tanaman hias belum menggunakan teknologi otomatisasi penyiraman tanaman hias, salah satunya dengan cara rancang bangun alat penyemprot tanaman otomatis berbasis arduino Uno. Alat tersebut menggunakan sensor DHT22 atau juga dikenal sebagai AM2032 adalah sensor yang dapat mengukur suhu dan kelembaban udara di sekitarnya sensor ini lebih akurat dan presisi. Pada penelitian terdahulu dengan judul Prototype Penyiraman Tanaman Otomatis Dengan Sensor kelembaban Tanah Berbasis Atmega 328. Manfaat alat penyiram tanaman anggrek otomatis yaitu bagi peneliti mendapatkan keterampilan pengalaman nyata serta permasalahan dan penanganan masalah yang dihadapi dalam dunia kerja, bagi universitas Dapat menjalin kerja sama antara Universitas dengan usaha petani tanaman hias serta dapat mempromosikan alat otomatisasi penyemprot tanaman, bagi masyarakat Mendapat pengalaman tentang alat otomatisasi penyemprot tanaman untuk membantu merawat tanaman. Penelitian yang dilakukan menggunakan metode Research and Development (Penelitian dan Pengembangan). Metode penelitian dan pengembangan (research and development) [2] termasuk dalam kategori penelitian "need to do" yaitu penelitian yang hasilnya digunakan untuk membantu pelaksanaan pekerjaan, sehingga kalau pekerjaan tersebut dibantu dengan produk yang dihasilkan dari R\&D maka akan semakin produktif, efektif dan efisien. Oleh karena itu metode penelitian dan pengembangan (R\&D) ini digunakan untuk penelitian penyusunan STD (Skripsi, Tesis, Disertasi) apabila peneliti atau mahasiswa bermaksud untuk menguji produk tertentu yang sudah ada, mengembangkan 
produk tertentu dan menemukan produk tertentu yang lebih efektif, baru dan original. Metode penelitian dan pengembangan (R\&D) adalah termasuk dalam metode penelitian kombinasi model sequentiall berurutan. Menjawab persoalan di atas, perancangan alat penyiram tanaman otomatis berdasarkan kondisi suhu dan kelembaban tanah berbasis arduino. Konsep dasar alat ini secara otomatis akan menyiram tanaman pada saat kondisi suhu dan kelembaban tanah kering. Sistem penyiraman tanaman anggrek otomatis menggunakan sensor suhu dan kelembaban untuk mendeteksi suhu dan kelembaban di daerah yang akan disiram. Apabila suhu dan kelembaban di ketegori kan melebihi batas minimum yang telah diatur pada program, yaitu $22^{\circ} \mathrm{C}$ pada pagi hari dan $35^{\circ} \mathrm{C}$ pada siang hari, maka sistem langsung bekerja. Penggunaan sensor suhu dan kelembaban pada sistem dimaksudkan agar penyiraman dilakukan pada kondisi suhu dan kelembaban yang tepat. Tinggi rendahnya suhu dan kelembaban menjadi salah satu faktor yang menentukan tumbuh kembang, reproduksi dan juga kelangsungan hidup tanaman. Pada umumnya suhu dan kelembaban yang baik bagi tumbuhan adalah antara $22^{\circ} \mathrm{C}$ sampai dengan $35^{\circ} \mathrm{C}$ dan kelembaban $\pm 65 \%$. Suhu dan kelembaban yang lebih atau kurang dari batas normal tersebut dapat mengakibatkan pertumbuhan yang lambat atau berhenti. Manfaat alat penyemprot tanaman otomatis memiliki kinerja yang memuaskan dan mampu melakukan penghematan air[3]. Keluaran dari sensor ini yaitu data digital yang sudah tidak membutuhkan ADC karena terkalibrasi secara otomatis[4].

\section{KAJIAN TEORI}

Sensor DHT22 adalah sensor digital kelembaban dan suhu relatif. Sensor DHT22 menggunakan kapasitor dan ter- mistor untuk mengukur udara disekitarnya dan keluar sinyal pada pin data. Sensor DHT22 juga sangat mudah diterapkan dalam mikrokontroller jenis Arduino karena memiliki stabilitas yang baik dan dapat dipercaya dan digunakan pada fitur kalibrasi degnan hasil sangat akurat. Jenis arduino tersebut adalah Arduino Uno. Arduino Uno ini merupakan sebuah papan minimum sistem mikrokontroler yang bsersifat open source. Kemudian arduino memiliki beberapa keistimewaan tersendiri jika dibandingkan dengan board mikrokontroler lainnya, dan pada Arduino ini telah dapat menggunakan bahasa pemrograman (programming) yang dirancang dengan menggunakan perangkat lunak[7].

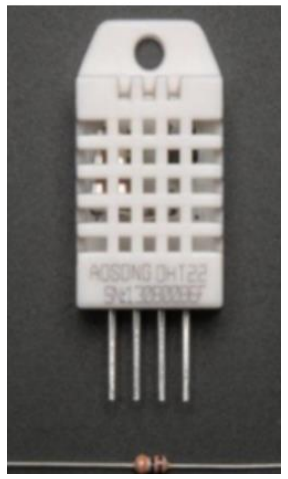

Gambar 1: Sensor DHT22 [10]

Di dalam board arduino itu sendiri memiliki loader yang berbentuk USB sehingga sangat memudahkan membuat sebuah program mikrokontroller pada Arduino tersebut. Ada penelitian terkait yang telah menggunakan Arduino Uno yaitu pembuatan rancangan pengukur suhu dan kelembaban dengan menggunakan Arduino dan DHT11 [8], serta pembuatan sistem smart farming berbasis arduino dan sensor DHT11 [9].

\section{METODE PENELITIAN}

Jenis penelitian ini adalah penelitian dan pengembangan (Research and Development). Metode penelitian dan pengembangan (R\&D) adalah metode penelitian yang digunakan untuk menghasilkan rancangan produk baru, menguji keefektifan produk yang telah ada, serta mengembangkan dan menciptakan produk baru. Ada tiga langkah penelitian dan pengembangan, yaitu dimulai dengan tahap planning (perencanaan), kemudian production (produksi), dan terakhir evaluation (evaluasi)[2].

Tahap planning, diawali dengan analisis kebutuhan yang dilakukan melalui studi literatur ataupun 
pengumpulan informasi yang berkaitan dengan penelitian untuk dilakukan perancangan. Selanjutnya dilakukan tahap production (produksi), pada tahap ini akan dilakukan pembuatan produk sesuai dengan rancangan yang telah dibuat. Adapun produk yang dirancang dalam penelitian ini adalah alat monitoring kelembaban tanah dan suhu udara berbasis Arduino Uno. Arduino ini merupakan sebuah board mikrokontroler yang didasarkan pada ATmega328. Board ini dapat terhubung ke 14 sinyal digital I/O dan 6 sinyal analog input, lalu board ini bersifat open-source dan bahasa pemrograman yang digunakan adalah $\mathrm{C}[6]$. Setelah tahap produksi selesai maka tahapan terakhir yang dilakukan adalah evaluation (evaluasi), pada tahap evaluasi ini dilakukan kegiatan pengujian produk, untuk menilai apakah produk yang telah dibuat bekerja dengan baik sesuai dengan tujuan yang telah ditentukan.

Dalam penelitian ini tahapan evaluasi dilakukan dengan cara pengujian produk secara keseluruhan. Untuk DHT22 sensor dilakukan teknik kalibrasi secara eksternal dengan cara menancapkan probe pada kondisi tanah yang berbeda mulai dari kondisi kering, lembab hingga basah.

\section{PERANCANGAN}

Berdasarkan pengamatan sebelumnya terhadap masalah dalam sulitnya monitoring kelembaban pada setiap tanaman, dimana setiap tanaman memiliki sifat dan karakteristik yang berbeda, penelitian ini memberikan solusi berupa solusi alternatif terhadap masalah yang dihadapi dengan menggunakan sensor dan microcontroller, yang dapat membantu dan memudahkan petani dalam melaksanakan monitoring kelembaban pada tanaman mereka. Dengan mengetahui nilai kelembaban tanah akan sangat bermanfaat untuk bisa menentukan langkah atau penanganan terhadap tanah tersebut. Pada sensor kelembaban tanah ini dimulai dengan teknik kalibrasi secara eksternal menancapkan probe pada kondisi tanah yang berbeda dan juga Kalibrasi pada arduino untuk menentukan batasan-batasan kelembaban pada tanah yang dibutuhkan oleh tanaman. Cara kerja dari DHT22 Sensor yaitu pada saat kondisi tanah basah dibawah nilai ambang, maka tegangan output akan turun, dan relay tidak menutup arus listrik sehingga buzzer tidak akan menyala. Begitu juga sebaliknya. Pada saat kondisi tanah kering diatas nilai ambang, maka tegangan output akan naik dan relay akan membuka arus listrik kepada buzzer dan buzzer akan menyala. Sistem yang akan dirancang mampu menampilkan informasi nilai kelembaban tanah yang dibutuhkan untuk menentukan langkah atau penanganan tanah sehingga monitoring secara realtime menjadi lebih efisien.

Dalam menganalisa sebuah sistem yang diajukan, penelitian diperlukan secara deskriptif memberikan penjelasan apa saja yang dilakukan oleh sebuah sistem. Penjelasan yang berupa gambar proses kerja sebuah sistem yang dibuat. Tujuan dari pembuatan flowchart adalah untuk mempermudah pembaca dan peneliti sistem itu sendiri untuk memahami langkahlangkah serta cara kerja sebuah sistem yang dibuat. Dari penelitian yang dilakukan menghasilkan flowchart, seperti gambar 2

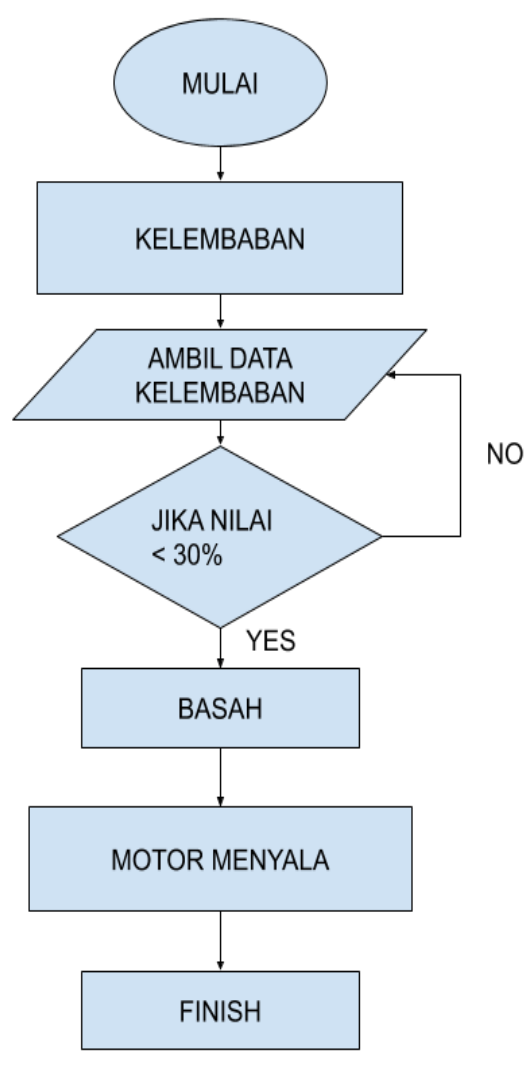

Gambar 2. Diagram Flowchart Sensor

Berdasarkan Gambar 1 terdapat kondisi decision dimana proses membutuhkan keputusan untuk 
menentukan langkah berikutnya. Dalam pernyataan apabila nilai > 30\% maka akan ada dua pilihan keputusan yaitu Jika nilai TIDAK lebih dari 30\%, maka langkah selanjutnya yang diambil adalah kering. Jika nilai BENAR lebih dari 30\%, maka langkah selanjutnya yang diambil adalah basah. Tahap selanjutnya dilakukan perancangan perangkat keras (hardware) dan perangkat lunak (software). Perancangan perangkat keras diawali dengan merancang diagram blok terlebih dahulu. Adapun diagram blok dari rancang bangun sistem monitoring kelembaban tanah dan suhu dapat dilihat pada gambar 3.

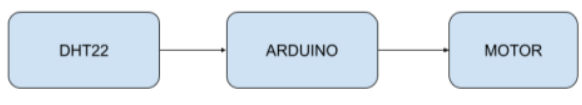

Gambar 3. Diagram Blok Rancangan

Selanjutnya dilakukan perancangan perangkat lunak (software). Perancangan perangkat lunak terfokus pada pemrograman Arduino dengan menggunakan perangkat lunak Arduino IDE (Integrated Development Environment) untuk membuat kode program seperti pada Gambar 4 dan Gambar 5. Sedangkan untuk perancangan elektronik pada alat ini dirancang dengan menggunakan aplikasi fritzing pada Gambar 5 dan disimulasikan menggunakan aplikasi proteus.

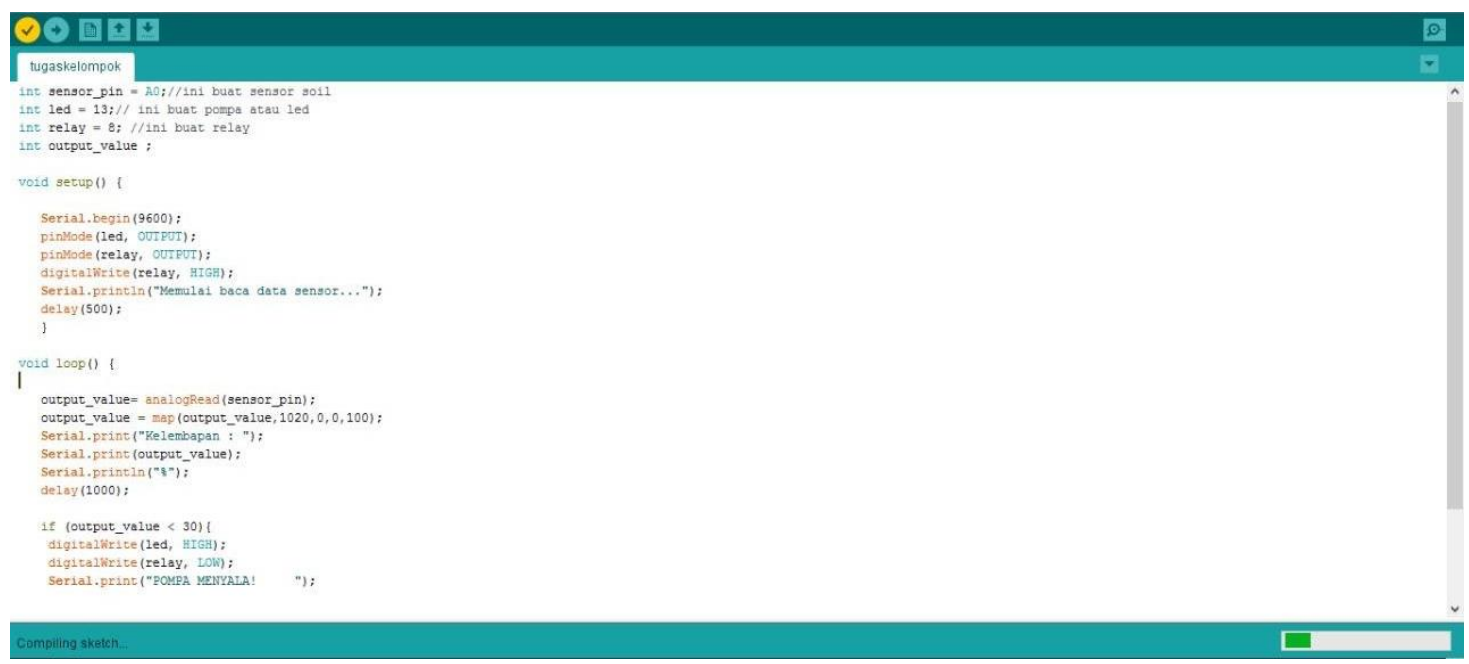

Gambar 4. Proses Compile pada Arduino IDE 


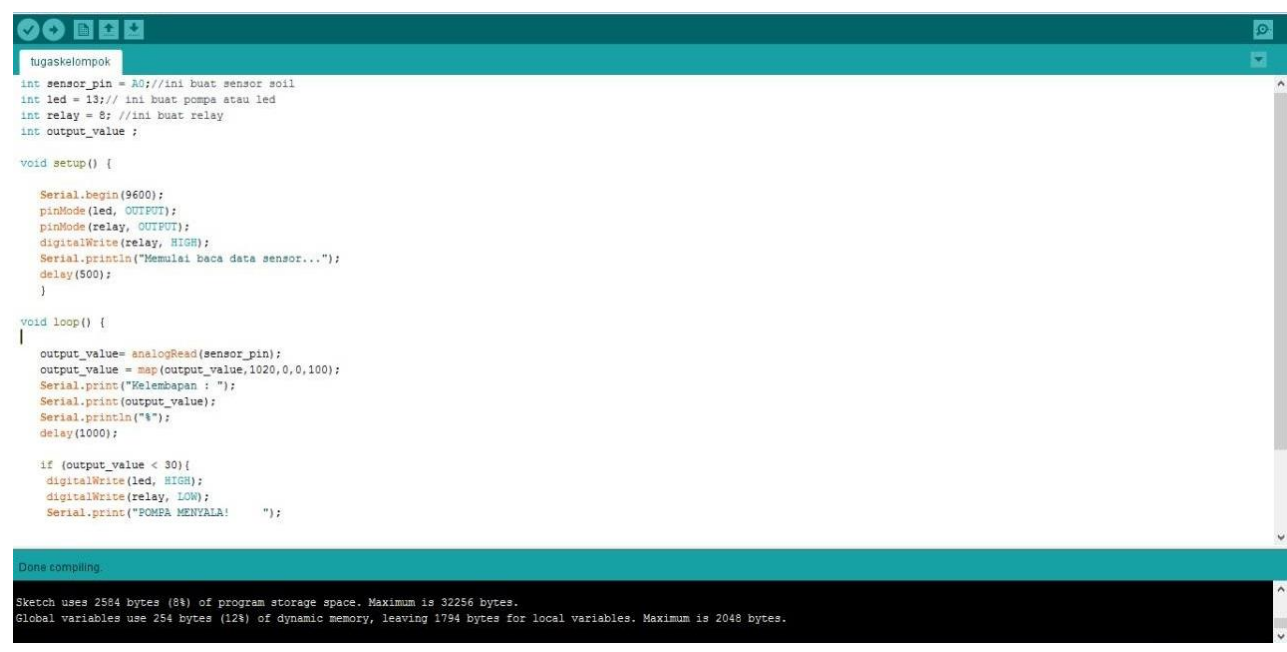

Gambar 5. Hasil Compile pada Arduino IDE

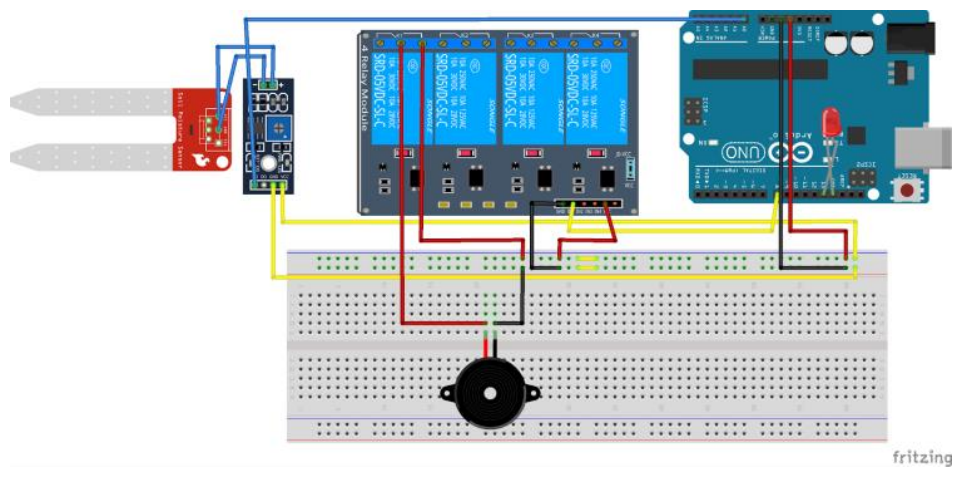

Gambar 6. Perancangan pada fritzing

\section{HASIL DAN PEMBAHASAN}

Tahapan selanjutnya Analisa alat yang digunakan. Pada tahapan ini akan dijelaskan alat - alat yang digunakan dan kegunaan pada setiap alat.

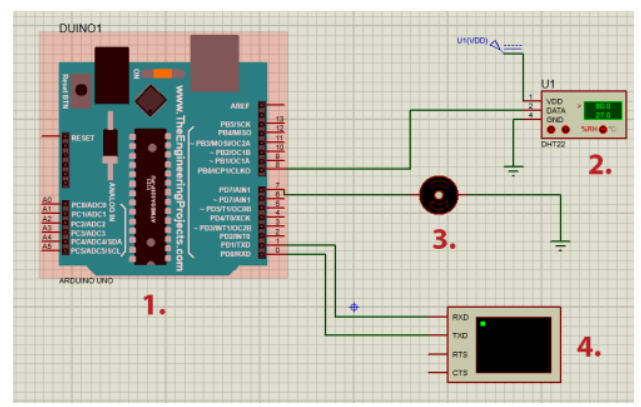

Gambar 7. Bagian-bagian pada rangkaian

\section{Keterangan:}

1. Arduino Uno

2. DHT22

3. Motor

4. Virtual Terminal

Setelah dijalankan maka hasil dari simulasi menggunakan proteus seperti berikut. 


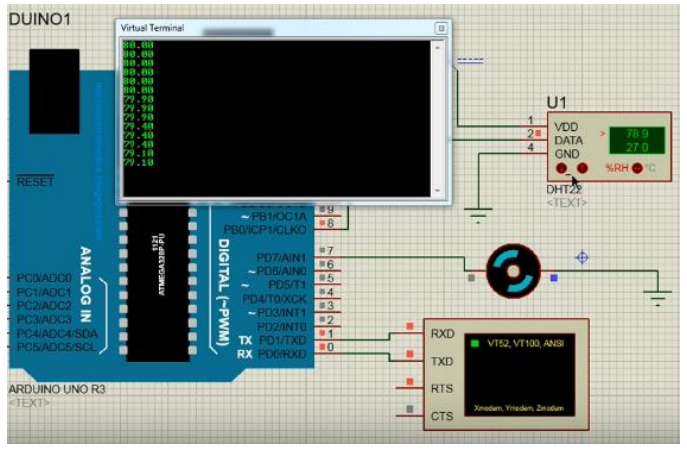

Gambar 8. hasil simulasi menggunakan proteus

\section{KESIMPULAN}

Menghasilkan alat penyiram tanaman anggrek otomatis yang dapat mengontrol dalam penyiraman tanaman anggrek sesuai dengan perubahan suhu dan kelembaban pada sekitar tanaman anggrek. Dari data suhu dan kelembaban yang dibaca oleh alat penyiram tersebut dapat disimpulkan bahwa rata - rata suhu dan kelembaban pada sekitar tanaman anggrek antara suhu $22^{\circ} \mathrm{C}-35^{\circ} \mathrm{C}$ dengan kelembaban antara $65 \%$ - $85 \%$ atau dalam keadaan lembab. Alat hanya mampu membaca suhu dan kelembaban pada sekitar tanaman anggrek tanpa menyimpan data dari perubahan keadaan sekitar.

Diharapkan untuk peneliti yang selanjutnya penyemprot tanaman anggrek otomatis bisa diberi blower agar tanaman anggrek lebih segar, bisa langsung kering air - air yang tersisa pada daun maupun pada bunga.Pengujian terhadap jenis tanaman anggrek berbeda diperlukan pengujian lanjutan terhadap masing - masing jenis tanaman anggrek yang berbeda.Untuk penelitian selanjutnya penyemprot tanaman anggrek otomatis bisa ditambah sensor untuk pengisian air otomatis.

\section{DAFTAR PUSTAKA}

[1]. Utama Satria, Sani M. Isa. 2006. Perancangan dan implementasi sistem otomatisasi pemeliharaan tanaman hidroponik. Hidroponik plantation and automatic. Tarumanegara

[2]. Sugiono. 2016. Cara Mudah Menyusun Skripsi, tesis, dan disertasi (STD).Universitas Bandung: ALFABETA.
[3]. Emir Nasrulloh, Agust Trisanto, Lioty Utami. 2011. Rancang bangun penyiraman tanaman otomatis menggunakan sensor suhu LM35 berbasis mikrokontroler ATMega8535. Universitas Lampung. Lampung.

[4]. J. Karunia (2019). Sensor DHT22.

[5]. Sugiyono. (2017). Metode Penelitian dan Pengembangan Research and Development. Bandung: ALFABETA.

[6]. M. Ichwan, M. G. Husada, M. I. A. Rasyid. Pembangunan Prototipe Sistem Pengendalian Peralatan Listrik pada Platform Android, Jurnal Informatika. 1 (2013), p. 13-25

[7]. Y. Zhou, Q. Zhou, Q. Kong, and W. Cai, "Wireless temperature \& humidity monitor and control system", 2012 2nd Int. Conf. Consum. Electron. Commun. Networks, CECNet 2012 - Proc., pp. 2246-2250, 2012.

[8]. D. Srivastava, A. Kesarwani, and S. Dubey, "Measurement of Temperature and Humidity by using Arduino Tool and DHT11", Int. Res. J. Eng. Technol., vol. 05, no. 12, pp. 876

[9]. M.K. Anushree and R. Krishna, "A smart farming system using Arduino based technology", Int. J. Adv. Res. Ideas Innov. Technol., vol. 4, no. 4, pp. 850-856, 2018.

[10].L. Abdulrazzak, I.A. Bierk, H. Aday, "Humidity and temperature monitoring", Int. J. Eng. Technol., vol. 7, no. 4, pp. 5174- 5177, 2018. 